\title{
Magnetic resonance imaging findings in the hyperacute phase of atypical femoral fracture: a case description
}

\author{
Kazuki Kobayashi, Yoichi Kaneuchi, Michiyuki Hakozaki^, Koji Otani, Shinichi Konno \\ Department of Orthopaedic Surgery, Fukushima Medical University School of Medicine, Fukushima, Japan \\ Correspondence to: Dr. Michiyuki Hakozaki. Department of Orthopaedic Surgery, Fukushima Medical University School of Medicine, 1 Hikarigaoka, \\ Fukushima-shi, Fukushima 960-1295, Japan. Email: paco@fmu.ac.jp.
}

Submitted Jun 25, 2020. Accepted for publication Jul 20, 2020.

doi: 10.21037/qims-20-794

View this article at: http://dx.doi.org/10.21037/qims-20-794

\section{Introduction}

In the treatment of metastatic bone tumors, bone-modifying agents (BMA) including bisphosphonates and denosumab is known to reduce the frequency of skeletal-related event including severe bone-related pain, hypercalcemia, spinal cord compression, or pathological fracture (1-3). Whereas, atypical femoral fracture (AFF) has been reported as an adverse event following the treatments with BMA. AFF is known to be a kind of stress fracture, and it usually shows typical imaging findings and clinical symptoms. Diagnosing $\mathrm{AFF}$ in the hyperacute phase by imaging modalities is challenging, but it is essential for preventing symptomatic fracture. We describe herein a patient with AFF without characteristic plain radiographic findings. However, his magnetic resonance imaging (MRI) showed a signal change at the lateral periosteum of proximal femoral diaphysis a few days before the symptomatic fracture, and the signal change was considered to be a significant MRI finding in the hyperacute phase of AFF.

\section{Case presentation}

A 67-year-old Japanese man presented with a three-month history of right proximal thigh pain without a history of trauma. Thirty-nine months ago, he was diagnosed with prostate cancer with multiple bone metastases including bilateral femur metastases, and he received chemotherapy with bicalutamide, luteinizing hormone-releasing hormone analog, and denosumab for 23 months. Plain radiographs of the right proximal femur showed a focal cortical thickening in the lateral subtrochanteric cortex (Figure 1A). MRI showed cortical thickening and bone edema in the subtrochanteric area (Figure $1 B, C, D)$. The patient was diagnosed with AFF and underwent prophylactic internal fixation with intramedullary nail (IMN). After the operation, the denosumab therapy was stopped. Seven months after the initial operation, left proximal thigh pain appeared. Plain radiographs of the left proximal femur showed no abnormality except preexisting osteoblastic metastasis (Figure 2A). MRI revealed a focal high intensity area along the lateral subtrochanteric periosteum on T2-weighted imaging and a short-tau inversion recovery (STIR) sequence, which was considered to be periostitis (Figure 2B,C). However, no bone edema was detected around the subtrochanteric region. Ten days after the MRI, the left subtrochanteric femoral fracture occurred following minimal trauma (Figure 2D). The transverse fracture was located in line with the hyperintense area along the lateral cortex of the subtrochanteric region on MRI. The patient was diagnosed with $\mathrm{AFF}$ and underwent internal fixation with IMN (Figure 2E). Postoperative rehabilitation with full weight-bearing and low-intensity pulsed ultrasound to accelerate bone healing were allowed from the day after surgery. Eleven months after the second surgery, the bone healing was delayed (Figure $2 F$ ) and the patient had a slight left thigh pain, but he was able to walk with a cane.

\footnotetext{
$\wedge$ ORCID: 0000-0003-1641-0795.
} 

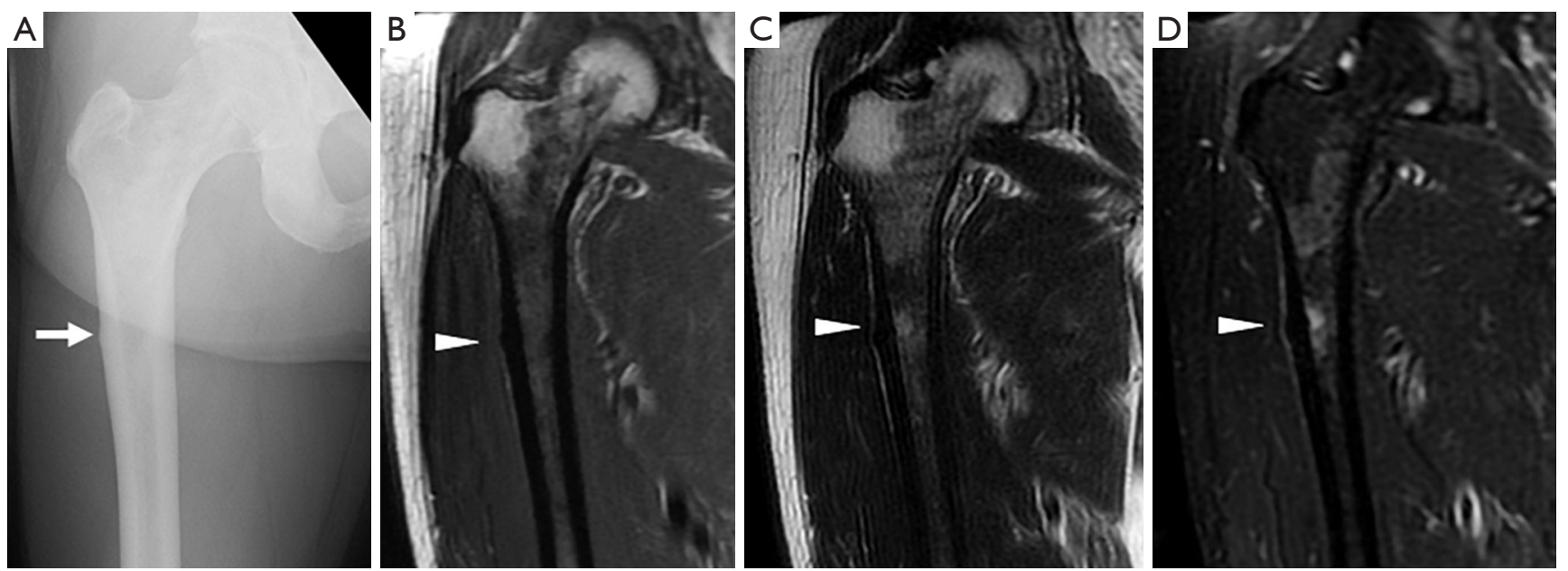

Figure 1 Plain radiograph of the right proximal femur (A) showing a focal cortical thickening in the lateral cortex of the subtrochanteric region (arrow). Coronal T1-weighted image (B), T2-weightied image (C), and short-tau inversion recovery (STIR) sequence (D) showing bone edema (arrowhead).

Written informed consent was obtained from the patient for publication of this study and any accompanying images. A copy of the written consent is available for review by the Editor-in-Chief of this journal.

\section{Discussion}

The patient meets all major criteria for the diagnosis of AFF (1). AFF is a fracture located along the femoral diaphysis between areas just distal to the lesser trochanter and just proximal to the supracondylar flare. AFF is associated with treatments using BMA including bisphosphonates or denosumab (1-3). Plain radiographs typically show a beak- or flare-like periosteal or endosteal callus in the lateral femoral cortex (4). MRI typically shows focal cortical thickening (periosteal and/or endosteal beaking) and bone edema (periosteal, endosteal, or marrow edema) $(5,6)$. In the present case, since prodromal symptoms such as pain over the lateral aspect of left the thigh were present, imaging studies were conducted. Although there was no finding that matched AFF on the plain radiograph, MRI revealed a slight signal change showing a thin highintensity area along the lateral subtrochanteric femoral cortex 10 days before the symptomatic fracture. Therefore, there is a possibility that this signal change on MRI reflected the presence of hyperacute AFF. If the patient with a history of treatment with BMA has prodromal symptoms and MRI shows a periosteal signal change along the femoral diaphysis, prophylactic internal fixation should be considered in order to prevent symptomatic AFF. 

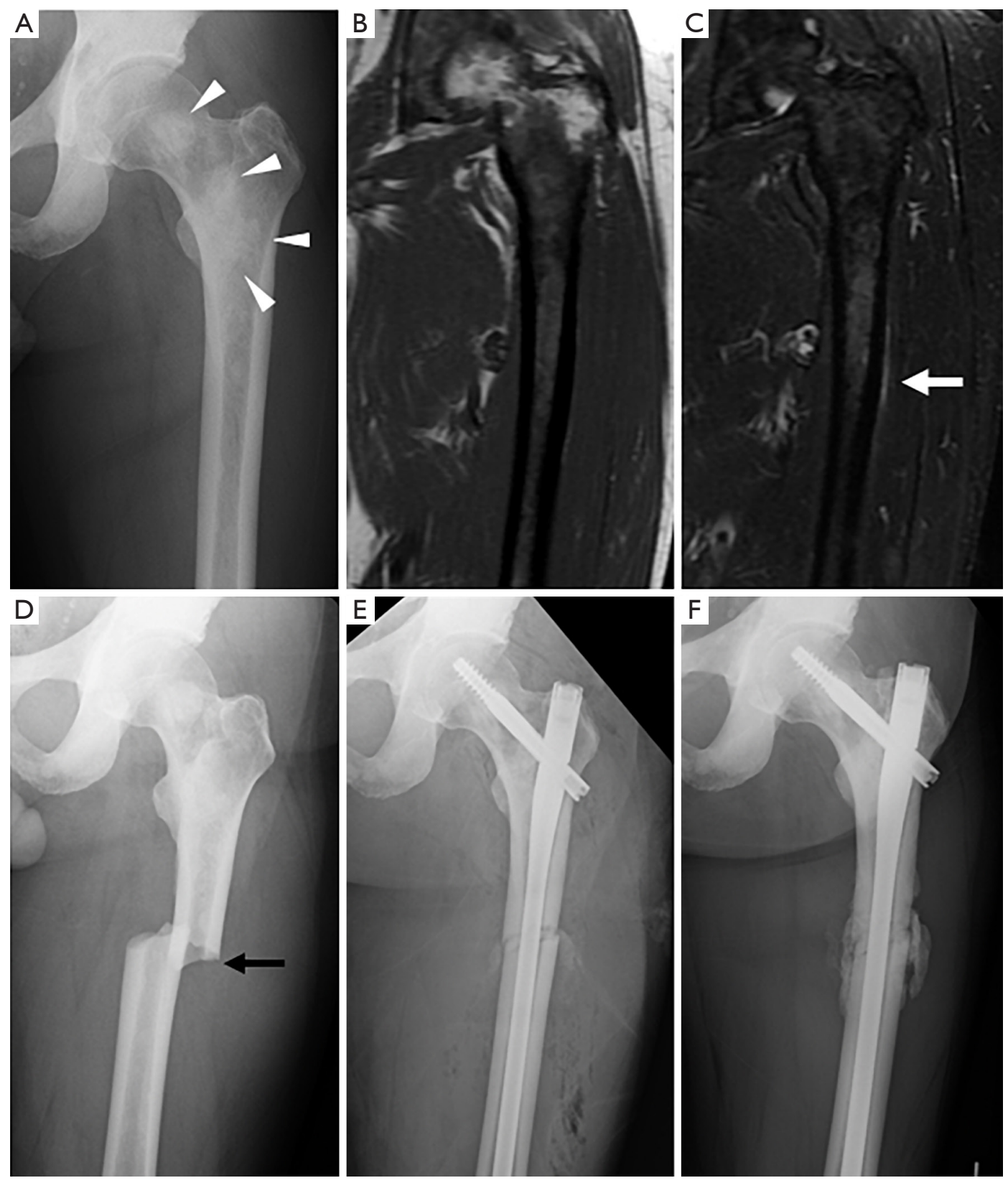

Figure 2 Plain radiograph of the left proximal femur (A) showing no abnormality excluding preexisting osteoblastic metastasis (arrowheads). Coronal T2-weighted images (B) showing no focal cortical thickening nor bone edema around the subtrochanteric region. STIR sequence (C) showing focal high-intensity area along the subtrochanteric lateral periosteum (white arrow). Plain radiograph 10 days after the MRI (D) showing transverse fracture located in line with the hyperintense area along the lateral cortex of the subtrochanteric area on MRI (black arrow). Plain radiograph obtained immediately after the internal fixation with intramedullary nail (E). Plain radiograph obtained 11 months after the surgery $(\mathrm{F})$ showing delayed bone healing. 


\section{Acknowledgments}

The authors thank the late Prof. Dr. Hideki Mizunuma for valuable discussions.

Funding: None.

\section{Footnote}

Conflicts of Interest: All authors have completed the ICMJE uniform disclosure form (available at http://dx.doi. org/10.21037/qims-20-794). The authors have no conflicts of interest to declare.

Informed Consent: Written informed consent was obtained from the patient for publication of this study and any accompanying images. A copy of the written consent is available for review by the Editor-in-Chief of this journal.

Open Access Statement: This is an Open Access article distributed in accordance with the Creative Commons Attribution-NonCommercial-NoDerivs 4.0 International License (CC BY-NC-ND 4.0), which permits the noncommercial replication and distribution of the article with the strict proviso that no changes or edits are made and the original work is properly cited (including links to both the formal publication through the relevant DOI and the license). See: https://creativecommons.org/licenses/by-nc-nd/4.0/.

\section{References}

1. Shane E, Burr D, Abrahamsen B, Adler RA, Brown TD,

Cite this article as: Kobayashi K, Kaneuchi Y, Hakozaki M, Otani K, Konno S. Magnetic resonance imaging findings in the hyperacute phase of atypical femoral fracture: a case description. Quant Imaging Med Surg 2020;10(12):2366-2369. doi: 10.21037/qims-20-794
Cheung AM, Cosman F, Curtis JR, Dell R, Dempster DW, Ebeling PR, Einhorn TA, Genant HK, Geusens P, Klaushofer K, Lane JM, McKiernan F, McKinney R, Ng A, Nieves J, O'Keefe R, Papapoulos S, Howe TS, van der Meulen MC, Weinstein RS, Whyte MP. Atypical subtrochanteric and diaphyseal femoral fractures: second report of a task force of the American Society for Bone and Mineral Research. J Bone Miner Res 2014;29:1-23.

2. Schilcher J, Aspenberg P. Incidence of stress fractures of the femoral shaft in women treated with bisphosphonate. Acta Orthop 2009;80:413-5.

3. Takahashi M, Ozaki Y, Kizawa R, Masuda J, Sakamaki K, Kinowaki K, Umezu T, Kondoh C, Tanabe Y, Tamura N, Miura Y, Shigekawa T, Kawabata H, Baba N, Iguchi $\mathrm{H}$, Takano T. Atypical femoral fracture in patients with bone metastasis receiving denosumab therapy: a retrospective study and systematic review. BMC Cancer 2019;19:980.

4. Yang KH, Min BW, Ha YC. Atypical Femoral Fracture: 2015 Position Statement of the Korean Society for Bone and Mineral Research. J Bone Metab 2015;22:87-91.

5. Png MA, Koh JS, Goh SK, Fook-Chong S, Howe TS. Bisphosphonate-related femoral periosteal stress reactions: scoring system based on radiographic and MRI findings. AJR Am J Roentgenol 2012;198:869-77.

6. Yang SP, Kim TW, Boland PJ, Farooki A. Retrospective Review of Atypical Femoral Fracture in Metastatic Bone Disease Patients Receiving Denosumab Therapy. Oncologist 2017;22:438-44. 